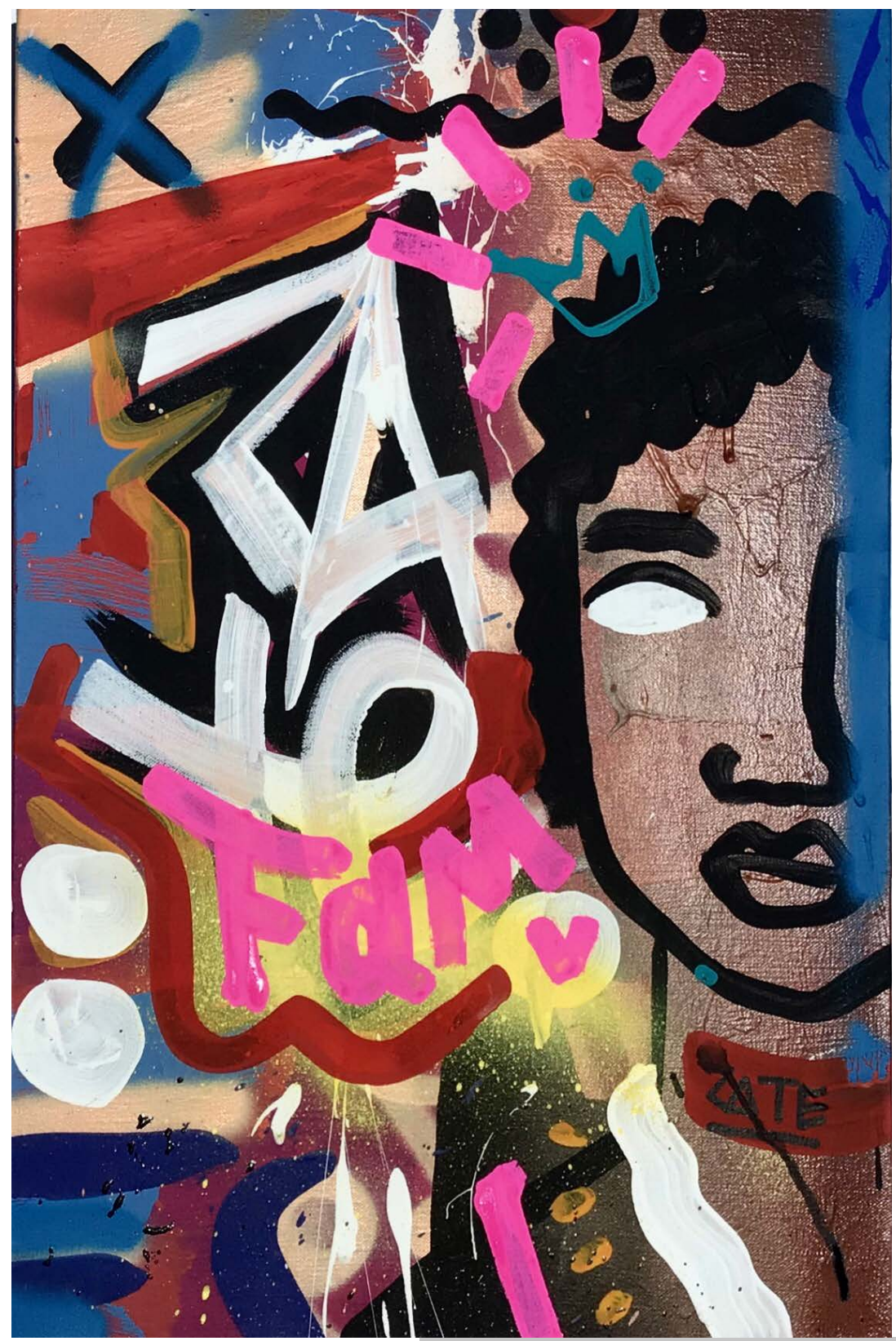

Artista invitado

Fabio Andrés Arboleda Mendoza

Zate FAM

Acrílico sobre lienzo

$35 \times 50 \mathrm{~cm}$

2021

Medellín 


\title{
La solución al problema de las drogas ilícitas en la construcción de paz. Desafíos en la implementación del Programa Nacional Integral de Sustitución de Cultivos Ilícitos (PNIS) en Colombia
}

\author{
Silvia Mantilla (Colombia)* \\ Tania Gisel Sastoque (Colombia)** \\ Sofía Quintero (Colombia) ${ }^{* * *}$
}

\section{Resumen}

Este artículo presenta un análisis de la formulación e implementación de los programas y políticas del posacuerdo en Colombia respecto al punto 4 del Acuerdo de paz entre el Gobierno de Colombia y las FARC-EP sobre la Solución al problema de las drogas ilícitas a partir del enfoque crítico de construcción de paz — paz liberal versus paz híbrida-. El análisis se desarrolla a partir de una metodología de enfoque cualitativo, un balance de políticas públicas y una sistematización de datos contrastados a partir de los enfoques teóricos. Se sostiene que, a pesar de la noción híbrida y contextualizada que evidencia el Acuerdo frente al desafío de los cultivos ilícitos, en la práctica la formulación e implementación del PNIS responde a la noción monoontológica y tecnocrática de la paz (neo)liberal. Esto se ha expresado en el corto plazo (2016-2020) a través de dos variables: a) la focalización del gasto como solución al problema de los cultivos y b) la participación comunitaria y legitimadora de la visión liberal en la implementación de los acuerdos colectivos y territoriales.

\section{Palabras clave}

Paz Negociada; Poscacuerdo; Drogas Ilícitas; Sustitución de Cultivos Ilícitos; Paz Híbrida; Colombia.

\footnotetext{
* Politóloga. Magíster en Estudios Latinoamericanos. Doctora en Migraciones y conflictos en la Sociedad Global. Docente e investigadora de la Facultad de Derecho, Ciencias Políticas y Sociales, e investigadora del Grupo de Investigación Nación Región y Relaciones Internacionales en América Latina y el Caribe, Universidad Nacional de Colombia-Sede Bogotá. Correo electrónico: scmantillav@ unal.edu.co - Orcid: 0000-0001-5645-3349 - Google Scholar: https://scholar.google.com.br/citations? user $=$ YwtEMugAAAAJ\&hl=es

** Estudiante de pregrado en Ciencia Política. Auxiliar de investigación, Universidad Nacional de Colombia-Sede Caribe. Correo electrónico: tgsastoquem@unal.edu.co - Orcid: 0000-0002-7500-8475

*** Estudiante de pregrado en Ciencia Política. Auxiliar de investigación, Universidad Nacional de Colombia-Sede Caribe. Correo electrónico: soquinterocr@unal.edu.co - Orcid: 0000-0003-1121-2458
} 


\title{
Cómo citar este artículo
}

Mantilla, Silvia; Sastoque, Tania Gisel y Quintero, Sofía. (2021). La solución al problema de las drogas ilícitas en la construcción de paz. Desafíos en la implementación del Programa Nacional Integral de Sustitución de Cultivos llícitos (PNIS) en Colombia. Estudios Políticos (Universidad de Antioquia), 62, pp. 184-213. https://doi.org/10.17533/udea.espo.n62a08

\section{The Solution to the Illicit Drugs Problem in Peace Building. Challenges in the National Comprehensive Program for the Substitution of Illicit Crops (PNIS) in Colombia}

\begin{abstract}
This article analyses the formulation and implementation of post-conflict policies in Colombia in relation to the section 4 of the Peace agreement between the government and the Revolutionary Armed Forces of Colombia (FARC-EP), which talks about "Solutions to illicit drug problems" based on the critical approach focused on peace building (Liberal Peace VS Hybrid Peace) suggested by Oliver Richmond (2015). The analysis develops from a methodology on qualitative approach, a balance from public politics and a systematization of contrasted data based on theoretical approaches. It is argued that, despite the hybrid and contextualized notion evidenced by the agreement on confronting illicit crops, in practice, the implementation of PNIS responds to the mono-ontological and technocratic notion of Neoliberal peace. This has been expressed in the short term (2016 - 2020) through two variables: 1. The targeting of spending as a solution to the problem of crops. 2 . Community legitimizing participation of the liberal vision in the implementing of the territorial collective agreements.
\end{abstract}

\section{Keywords}

Negotiated Peace; Post-Conflict; Illicit Drugs; Substitution of Illicit Crops; Hybrid Peace; Colombia. 


\section{Introducción}

En 2016 el Gobierno colombiano y la guerrilla de las Fuerzas Armadas Revolucionarias de Colombia-Ejército del Pueblo (FARC-EP) firmaron un acuerdo de paz que tenía como objetivo acabar con cincuenta años de conflicto armado interno (Gobierno de Colombia y FARC-EP, 2016). El Acuerdo de paz recogió los puntos neurálgicos que la sociedad civil definió como prioritarios en la búsqueda de una sociedad en paz, incluyente y equitativa, entre ellos: a) una reforma rural integral orientada a la transformación estructural del campo colombiano como factor originario de la confrontación armada; b) una apertura democrática para construir paz a través de la participación política ampliada e incluyente; c) un cese al fuego y de hostilidades centrado en la dejación de armas de los actores armados; y finalmente d) una solución al problema de las drogas ilícitas, en tanto combustible para la economía de guerra. Sobre este último punto, Colombia tiene ya una larga trayectoria que inicia en la década de 1970, al posicionarse como líder de la producción mundial de drogas ilícitas -inicialmente de marihuana y posteriormente de cocaína- lo cual ha implicado la implementación de una serie de políticas antinarcóticos y contrainsurgentes que han transitado desde la contención y la erradicación

[186 ] hacia la criminalización de toda clase de factores vinculados a los cultivos de uso ilícito, en un contexto altamente represivo e intervencionista dominado por el enfoque prohibicionista de Estados Unidos.

En el actual contexto de posacuerdo, la política para enfrentar el desafío de las drogas ilícitas se concentra en el Programa Nacional Integral de Sustitución de Cultivos Ilícitos (PNIS), el cual se considera un componente de la Reforma Rural Integral (RRI) -Punto 1 del Acuerdo de paz-, y que al recoger las visión holística y comprensiva de los actores sociales y comunidades en los territorios representa un giro radical con respecto a las políticas de drogas tradicionalmente implementadas en Colombia, pues propone una perspectiva de transformación de los territorios afectados por la producción y comercialización de los cultivos de uso ilícito que trasciende las concepciones tradicionales de participación, seguridad y prohibicionismo, al privilegiar un enfoque de salud pública (Méndez, Silva y González, 2019).

Las perspectivas de los programas de desarrollo alternativo mediante los que se ha buscado hacer frente al problema de los cultivos ilícitos en 
Colombia, han privilegiado un enfoque top-down, ${ }^{1}$ con diseños cada vez más estandarizados y poblaciones más focalizadas, transitando de un modelo de desarrollo rural en la década de 1980 a uno de lucha antinarcóticos y contrainsurgente en las décadas posteriores a 2000 (Rocha, 2016). Por lo anterior, una efectiva implementación del PNIS implicaría una redefinición de la acción del Estado en términos de paz, seguridad y desarrollo.

Cuatro años después de la implementación del PNIS (2016-2020), el área sembrada de cultivos ilícitos en Colombia pasó de 171000 ha en 2017 a 154000 ha en 2019, es decir, hubo una reducción de 9\% de los cultivos, lo cual supuso un freno a la tendencia al alza que inició en 2014 y llegó a su punto más alto en 2017 (UNODC, 2020). Pese a lo anterior, el propósito inicial del gobierno de Iván Duque de sustituir 50000 ha en el primer año de implementación del PNIS ha sido un fracaso, ya que en cuatro años tan solo se ha logrado una reducción de 17000 ha (Semana, 2020, junio 17). En la actualidad, Colombia sigue ocupando el lugar de mayor y más estable productor mundial de drogas (DW, 2020, junio 17), pues aunque se registra una menor área cultivada, la producción de cocaína se mantiene estable por «una mayor productividad de los lotes de coca en zonas muy específicas que pueden considerarse como enclaves productivos» (Radio Nacional, 2020, junio 17). Esto incluye los incrementos significativos de coca en departamentos como Norte de Santander (24\%) y Valle del Cauca (82\%) (UNODC, 2019).

El particular fracaso de las estrategias implementadas en los principales municipios cocaleros a través del PNIS, también revela un déficit de legitimidad social que procure incluir las visiones localizadas, contextualizadas y participativas que están contenidas en el Acuerdo de paz. Esto se evidencia entre otros aspectos, en el desfase del programa respecto de los objetivos de la RRI, en el enfoque asistencialista y de focalización neoliberal de recursos que privilegia el programa, en la desarticulación de los mecanismos participativos que deberían regular y en la intensificación de la represión y la violencia ejercida sobre las comunidades cocaleras.

Todos estos elementos permiten a afirmar que la no solución al problema de las drogas ilícitas en Colombia se debe, en parte, al tipo de

\footnotetext{
${ }^{1}$ Se refiere a la implementación de políticas diseñadas de «arriba hacia abajo», es decir, desde los actores gubernamentales y tecnocráticos que introducen sus enfoques, políticas y estrategias sin considerar el conocimiento o condiciones de las bases sociales, que se convierten en receptoras pasivas de tales políticas.
} 
formulación en la política pública que definió los parámetros de diseño e implementación del PNIS, que está posiblemente vinculado a lo que aquí se denomina una noción de "paz liberal», derivada de la arquitectura de la gobernanza internacional en el manejo de conflictos que surgió en la década de 1970 y que ha tenido desarrollos posteriores para garantizar la promoción del sistema democrático y neoliberal. Este concepto de «paz liberal» alude a la institucionalización de un abordaje tecnocrático e ideológico orientado a consolidar un modelo universal de Estado liberal en lo político y neoliberal en lo económico, fundamentado en las categorías de democracia, desarrollo y liberalización económica, donde la resolución de conflictos ha adoptado un modelo insensible con las diferencias contextuales de cada país y cada región (Richmond, 2006).

Se puede afirmar que el PNIS formulado durante el gobierno de Juan Manuel Santos (2016-2018) e implementado en el gobierno de Iván Duque (2018-2020) deriva, según los postulados teóricos expuestos en este artículo, de una concepción liberal de paz subsumida en el discurso hegemónico de la seguridad internacional — guerra contra el narcotráfico y el terrorismo-que se sustenta en el prohibicionismo y la criminalización del fenómeno. Este discurso es opuesto a las visiones que las comunidades locales cocaleras y la [188] sociedad civil en general tienen de la seguridad y la paz en sus contextos de desarrollo y que intentaron dejar plasmadas en el Acuerdo.

En este sentido, existen perspectivas teóricas y académicas que proponen la idea de una «paz híbrida» como apuesta ontológica orientada a superar, cuestionar y deconstruir los marcos normativos e institucionales de la aproximación liberal de la paz y la seguridad. Desde allí, la construcción de paz implica ensamblajes temporales y espaciales que rescatan el papel de las sociedades y su historia, su carácter contextual y una hibridación entre los conocimientos locales y las prácticas internacionales que legitima la agencia de los sujetos y los procesos multinivel de construcción del propio Estado (Richmond, 2015; Lederach, 2012; Mac Ginty, 2010, 2012; Mac Ginty y Sanghera, 2012).

El objetivo de este artículo es justamente caracterizar y diferenciar los enfoques que, en la dicotomía entre el modelo de la paz liberal y la apuesta de una paz híbrida, se presentan en la formulación, tanto del PNIS programa gubernamental- como en la noción ontológica que se desprende de la participación de los actores sociales en torno al Acuerdo de paz, en relación con el punto 4 sobre la solución al problema de las drogas ilícitas. 
La hipótesis central es que la posibilidad de construcción de una "paz híbrida» en el contexto del posacuerdo colombiano se ve fortalecida inicialmente por el enfoque de descentralización, participación, salud pública, despenalización y la comprensión «glocal» del fenómeno de las drogas ilícitas efectivamente reflejado en la negociación del punto 4 del Acuerdo. En la práctica, no obstante, la implementación de las reformas (2016-2020) se quiebra ante la noción monoontológica de la paz liberal, que en el corto plazo se ha manifestado a través de dos variables: a) la focalización del gasto como solución neoliberal, asistencialista y segmentada del PNIS y b) la variable de la participación legitimadora, cuyo énfasis en la recolección de datos y la concreción numérica de acuerdos con las comunidades cocaleras presenta serias deficiencias en los procesos locales de concertación y participación para la sustitución de cultivos en un contexto de bajos niveles de asociatividad y límites impuestos por la transformación de las violencias locales. Estas dos variables operan dentro de los límites impuestos por la lógica liberal, prohibicionista y el enfoque punitivo de la gobernanza nacional - gobierno de Iván Duque (20182021) - e internacional de la guerra contra las drogas.

Para la elaboración de este artículo se utilizaron fuentes de primera y segunda mano -informes oficiales y datos gubernamentales sobre la implementación del PNIS y sus resultados, así como libros y revistas académicas referidos a los debates teóricos recientes sobre construcción de paz-. Se planteó un ejercicio de análisis teórico de formulación e implementación de políticas públicas sobre drogas ilícitas en Colombia y su relación con los debates sobre modelos de desarrollo, para finalmente sistematizar la información y los resultados en matrices que reflejan una perspectiva comparada de enfoques y variables sobre neoliberalismo y construcción de paz.

\section{De la «paz liberal» a la «paz híbrida» en las teorías sobre construcción de paz}

La Ilamada "paz liberal» es un paradigma que ha imperado en el campo de las políticas de seguridad y resolución de conflictos desde la posguerra fría, pero que incluso tiene sus orígenes en la tradicional noción de «paz perpetua» de Immanuel Kant en un contexto de diversas disputas y conflictos bélicos internacionales del siglo xVIII, al proponer un proyecto de gobierno mundial que concrete una paz permanente entre los Estados. Su apuesta filosófica es considerada idealista, en tanto sostiene que los seres 
humanos estamos más orientados hacia la conservación, la cooperación y la supervivencia (Ravioli y Zabalza, 2005).

También se utilizó esta noción durante la Primera Guerra Mundial, bajo el liderazgo de Woodrow Wilson — presidente de Estados Unidos (1913-1921) - y su idea de la construcción de una paz cosmopolita mundial a ser instaurada mediante el Tratado de Versalles (Triana, 2014). Aunque la Segunda Guerra Mundial evidenció el fracaso de las nociones idealistas de la paz liberal, el paradigma adquirió mayor posicionamiento durante la Guerra Fría, con el auge de la Organización de las Naciones Unidas (ONU) -y sus misiones de paz- y más específicamente durante la década de 1970, en el marco de las discusiones que, desde el paradigma realista de las relaciones internacionales, proponían las teorías de la «paz democrática» (Doyle, 1983a; 1983b; Russett, 1993a; 1993b; 1993c).

La teoría de la paz democrática constituyó una valiosa aportación por parte de su creador moderno Michael W. Doyle, que posteriormente fue revisada por Bruce Russett y Rudolph Rummel. En el marco de las discusiones sobre la anarquía de los Estados dentro de la teoría realista de las relaciones internacionales, la teoría de la paz democrática sostiene que las

[190 ] democracias tienden a comportarse en materia de política exterior de manera tal que puedan alcanzar las condiciones de resolución de las crisis entre los Estados sin tener que recurrir al uso de la fuerza. Esta disposición debería ser causada por algunos factores estrechamente vinculados al régimen político democrático (Gobetti, 2009).

Dichas nociones liberales de la paz, que además se constituyeron en el principio filosófico de la llamada «exportación de la democracia» en Estados Unidos, fueron resignificadas en la década de 1990 con los aportes de la teoría del neoliberalismo institucional (Keohane, 1989). Aunque esta teoría se basa en el supuesto realista de que los Estados son agentes racionales y egoístas, da relevancia a las formas de cooperación representadas en las instituciones -internacionales_ que facilitan la maximización de oportunidades y beneficios para los actores que ejercen el poder dentro del sistema (Keohane, 1989).

De este modo, las nociones de democracia representativa, derechos humanos, buen gobierno, desarrollo y liberalización económica (Triana, 2014) se constituyeron, tanto en lo teórico como en lo político, en los pilares fundamentales de la paz liberal. 
En el terreno teórico y académico, no obstante, han surgido apuestas críticas que buscan deconstruir los marcos conceptuales, normativos e institucionales de la noción liberal de paz. La literatura reciente que se desprende de este ejercicio se desarrolló inicialmente en torno a las discusiones sobre acciones promovidas dentro de las llamadas operaciones de paz, como aquellas lideradas por Naciones Unidas u otras organizaciones internacionales que privilegiaban el llamado enfoque de "construcción de paz» - peace building_- Posteriormente, la literatura ha sido validada para analizar situaciones en contextos particulares de reformas asociadas a posacuerdo en diversos lugares del mundo.

En este sentido, Oliver Richmond (2010a; 2010b; 2011a; 2011b; 2012; 2013; 2015) y otros autores (Mac Ginty, 2010; 2012; Mac Ginty y Sanghera, 2012; Pugh, 2011) sostienen que la «paz liberal» es el resultado de una arquitectura de la gobernanza internacional que se ha convertido en un lugar de securitización, cuya principal preocupación, por un lado, es conservar la jerarquía internacional de normas y marcos regulatorios de la seguridad, y por otro, estabilizar a las periferias. La teoría de la securitización tiene como antecedente la dirección que la política de la seguridad tomó durante la Guerra Fría, lo cual supuso la visión militarista de esta. Desde el neorrealismo se hallan las contribuciones de Ole Wæver y Barry Buzan y en la Escuela de Copenhague. La teoría surge de las críticas a la gestión tradicional sobre la seguridad. Estas visiones implican ver la seguridad más allá de las reglas de juego tradicionales de definir o identificar un asunto como amenaza, lo que implica que se cierren espacios de debate y deliberación. Así que seguir una línea diferente resulta en la desecuritización (VerdesMontenegro, 2015, pp. 115-120).

En términos generales, se trata de una aproximación tecnocrática que garantiza reformas y programas orientados al posacuerdo, con un carácter neoliberal en lo económico y liberal en lo político. Este modelo ha exacerbado las condiciones de desigualdad en países en proceso de pacificación, en tanto impone la sofisticación normativa del Norte y profundiza la opresión y la injusticia en los países del Sur global a través del rechazo a la tradición y al comunalismo en defensa de la modernidad y del individualismo (Richmond, 2015). A menudo, bajo este modelo, la paz se convirtió para estas poblaciones en nuevas formas de violencia, vulnerabilidad, conflictividad y desamparo, así como en un nuevo discurso dominante frente al cual resistirse (Mac Ginty, 2010; 
2012; Mac Ginty y Sanghera, 2012; Richmond, 2010a; 2010b; 2011a; 2011b; Pugh, 2011).

Frente al caso latinoamericano, autores como Sabine Kurtenbach (2010) manifiestan, por ejemplo, la dificultad para la construcción de una paz híbrida en el contexto centroamericano, donde el modelo de la paz liberal tuvo manifestaciones inesperadas en los conflictos de Nicaragua, Guatemala y El Salvador, evidenciando los fracasos en materia de seguridad. En lo concerniente al caso de Colombia, Jairo Agudelo y Davide Riccardi (2019) también han advertido sobre los efectos negativos de la cooperación y la implementación de programas en el conflicto colombiano por parte de Estados Unidos y la Unión Europea, y cuyas manifestaciones tienden a alejarse de lo que implica una paz estable y duradera.

Frente al nocivo modelo de la paz liberal, Richmond (2013) y otros autores (Mac Ginty, 2010; 2012; Mac Ginty y Sanghera, 2012; Pugh, 2011) proponen la idea de una «paz híbrida» a través de un significado de paz que implica un ensamblaje entre lo histórico, lo local, lo social, lo económico, la movilización civil, el agenciamiento de la paz, la coexistencia, los derechos, las necesidades y la legítima autoridad, y que todo lo anterior puede ser [192] soportado internacionalmente.

La paz híbrida o contextualizada enfatiza, por tanto, en la intersección o combinación de elementos y formas de legitimación locales — bottom-up_ con instituciones, normas y estándares procedentes de las organizaciones internacionales y los Estados -top-down-, pues para su consolidación requiere que los actores internacionales sean capaces de superar su intervencionismo y actúen de forma que respeten la cultura local, los sistemas locales de conocimiento, legitimidad y autoridad (Richmond, 2012; 2013). Se trata también de identificar las complementariedades y tensiones que ocurren en los procesos multinivel de construcción del Estado, las expectativas del desarrollo económico y la misma construcción de paz, lo cual supone desplazarse desde una concepción negativa de paz hacia una visión positiva.

Desde una crítica al maximalismo de la paz positiva de Johan Galtung, autores como Charles Call y Elizabeth Cousens (2008) y David Malone y Heiko Nitzschke (2009) parten de la necesidad de transformar las dinámicas de gobernanza sin trascender la noción de paz negativa, lo que implica también reconocer las falencias de gobernabilidad en los conflictos armados. 
Estos enfoques son importantes para la comprensión de la operación e implementación del PNIS en los territorios, considerando las condiciones necesarias para superar la violencia desde la gestión de economías y alternativas de desarrollo.

La apuesta por el enfoque de la paz híbrida puede llevar a reflexiones de orden ontológico y epistemológico sobre cómo generar ciencia en materia de posacuerdos, paz y seguridad. Esto solo puede lograrse a través de una mirada crítica de los paradigmas sobre los que se fundan las políticas públicas y las reformas estatales en contextos de desarrollo neoliberal. También implica desvelar las concepciones y dispositivos que regulan los discursos y retóricas estatales de la seguridad que requieren de enfoques cada vez más amplios en lo teórico, pero más diferenciales y regionalizados en la praxis como alternativa para construir conocimiento y visiones de paz y desarrollo desde los espacios de legitimación-deslegitimación de la violencia —armada, estatal, epistémica- y de resistencia social.

Cabe anotar que, incluso bajo la noción ideal de una «paz híbrida» y contextualizada, las complejidades en las que se inscribe el cultivo de coca en los distintos territorios colombianos, junto con las disímiles legitimidades que los atraviesan (Ciro, 2016) y la gran diversidad de actores, representan desafíos culturales y dilemas al desarrollo que escapan a formas rigurosas de comprensión de fenómenos tan complejos como la violencia, las formas organizativas o el asistencialismo del Estado colombiano en los territorios cocaleros.

Construir un corpus teórico, analítico y político del fenómeno de los cultivos ilícitos en Colombia supone un ejercicio crítico y deconstructivo, lo cual será objetivo del siguiente apartado, al analizar la formulación de las reformas y programas asociados al punto 4 del Acuerdo de paz para esclarecer las visiones ontológicas que orientan las acciones gubernamentales y las sociales en la dicotomía entre la noción de paz liberal y la versión más crítica de una paz híbrida.

\section{El punto 4 del Acuerdo de paz: hacia un enfoque de construcción de una paz híbrida y contextualizada}

Lo establecido en el punto 4 del Acuerdo de paz evidencia una nueva concepción frente al problema de las drogas y los cultivos de uso ilícito en 
Colombia y sus posibles soluciones en un marco de posacuerdo, además del reconocimiento de las históricas condiciones de marginalidad y pobreza que facilitaron la vinculación de poblaciones vulnerables con las economías ilegales, es decir, las denominadas condiciones causales del conflicto. El acuerdo entre el Gobierno y las FARC-EP plantea visiones alternas a partir de un enfoque territorial y con participación ciudadana.

En primer lugar, resulta importante evidenciar la concepción descentralizada que se incorpora en el punto 4 del Acuerdo. Bajo este marco, se resaltan las potencialidades del acuerdo en materia de construcción territorial de alternativas ya incorporadas en el PNIS (Rocha, 2016) y se enfatiza en la importancia de generar estrategias desde el reconocimiento de los condicionantes contextuales del cultivo y el mercado de las drogas en Colombia para que programas como el PNIS funcionen (Insuasty y Sánchez, 2018, octubre 29). Esto pretende sentar sus bases bajo criterios como la gestión local y enfoques que parten desde el bottom-up propuestos por Galtung y retomados por autores como Richmond en sus análisis posteriores.

En segundo lugar, el tema de los cultivos de uso ilícito es abordado en el Acuerdo con un enfoque transversal a la RRI, el cual busca realizar [194] una articulación entre los programas de nueva ruralidad y transformación del campo colombiano en aras del buen vivir de los ciudadanos, particularmente de aquellos que han sido víctimas del histórico conflicto armado y sus dinámicas derivadas. Como resultado de esta articulación surge el PNIS, que desde el ámbito nacional trabajaría en conjunto con los Planes Integrales de Sustitución y Desarrollo Alternativo (PISDA), en relación con las zonas beneficiadas por los Planes de Desarrollo con Enfoque Territorial (PDET). En este sentido, el acuerdo plantea cierto nivel de descentralización en la búsqueda de soluciones en torno a las particularidades de los territorios cocaleros.

El postconflicto (sic) abre la posibilidad para que las políticas e institucionalidad para el control de los cultivos de coca, inicien el tránsito desde la órbita de las políticas de control de la oferta y la estrategia contrainsurgente, hacia las políticas relacionadas con el desarrollo rural, el ordenamiento territorial y la promoción de los derechos humanos. Además, la instrumentación migraría desde esquemas transitorios y centralizados en la Presidencia de la República, hacía arreglos institucionales permanentes y descentralizados; desde programas diseñados desde arriba hacia abajo, con una oferta 
estandarizada y secuenciada hacia productos que se adapten a las necesidades de los diferentes territorios e intensivos en participación comunitaria (Rocha, 2016, p. 23).

En tercer lugar, la creación de espacios de participación ciudadana como las asambleas departamentales y municipales vinculadas al PNIS ha dado lugar al involucramiento de las comunidades en los procesos de sustitución voluntaria y ha fomentado la vinculación de las familias a estos proyectos, ${ }^{2}$ además de generar espacios para su monitoreo y evaluación como los Consejos Asesores Territoriales, las Comisiones Municipales de Planeación Participativa y los Consejos de Evaluación y Seguimiento. Por otra parte, el Acuerdo realiza un especial énfasis en el enfoque diferencial de género, sustentado también en consideraciones de tipo étnico, condiciones materiales y ubicación geográfica, lo que implica pensar en instituciones más incluyentes y holísticas en la concepción y reformulación de problemas y soluciones beneficiosas para las comunidades.

Adicionalmente, un aspecto que vale la pena resaltar en la formulación del problema es el reconocimiento que realiza el Acuerdo del tratamiento diferencial a los eslabones menores afectados por los cultivos, además de un enfoque de salud pública en lo referente a la prevención y no estigmatización de consumidores. Esta noción dista considerablemente de la concepción reinante tradicionalmente respecto a la criminalización de consumidores, cultivadores, recolectores y otros oficios conexos, quienes en muchos casos fueron sujetos penalizados o víctimas de las aspersiones aéreas con glifosato como mecanismo de erradicación forzada.

En cuanto a la visión internacional del fenómeno, el Acuerdo enfatiza el enfoque de corresponsabilidad y de la articulación entre países productores y consumidores en la formulación de una política antidrogas eficiente, considerando así los errores precedentes de intentos de erradicación desde la criminalización y la militarización de las zonas cocaleras. El gobierno de Juan Manuel Santos (2010-2018), líder de la negociación, se caracterizó por un alineamiento crítico respecto de la gobernanza internacional del fenómeno mundial de las drogas y del esquema de dependencia países productores-países consumidores, proponiendo un cambio de visión en

\footnotetext{
${ }^{2}$ Las familias inscritas en el PNIS son 99 097, de las cuales 67251 son cultivadores ilícitos. Las demás familias corresponden a no cultivadores (14 989) y recolectores (16 857) y UNODC solamente monitorea 82240 familias cultivadoras y no cultivadoras (UNODC, 2020).
} 
el que se establece que el fenómeno no es un crimen, sino un problema de salud pública. ${ }^{3}$ No obstante, el arribo de Iván Duque a la Presidencia significó un salto en la dirección opuesta. En la política Ruta hacia el Futuro desarrollada por su gobierno se retomó una visión de la erradicación forzada terrestre o por aspersión y en lo que concierne al PNIS:

Primero, decidió que no se admitirían más inscritos al programa y cambió su estatus administrativo [...]. El decreto 179/2019 suprimió la DSCI Dirección de Sustitución de Cultivos de Uso llícito] y dejó el programa en manos de la CPEC [Consejería Presidencial para la Estabilización y Consolidación]. Segundo, impulsó la reanudación de las fumigaciones, lo cual pondría en peligro los planes de sustitución de las familias inscritas (Gutiérrez, Machuca, y Cristancho, 2019, p. 146).

Cuadro 1. Comparación de los enfoques sobre paz híbrida y paz liberal en la formulación e implementación del punto 4 del Acuerdo de paz (PNIS).

\begin{tabular}{|c|c|c|}
\hline $\begin{array}{c}\text { El Acuerdo de paz } \\
\text { sobre el fenómeno } \\
\text { de los cultivos de uso } \\
\text { ilícito }\end{array}$ & $\begin{array}{c}\text { Avances del PNIS } \\
\text { en el posacuerdo } \\
\text { Enfoque de paz híbrida }\end{array}$ & $\begin{array}{l}\text { Desafíos del PNIS } \\
\text { en el posacuerdo } \\
\text { Enfoque de paz liberal }\end{array}$ \\
\hline $\begin{array}{l}\text { - Origen e historia del } \\
\text { cultivo ilícito: pobreza, } \\
\text { marginalidad, débil } \\
\text { presencia institucional. } \\
\text { - Vinculación con } \\
\text { la RRI, concepción } \\
\text { amplia del problema } \\
\text { del campo. }\end{array}$ & $\begin{array}{l}\text { - Construcción horizontal y } \\
\text { participativamente, además } \\
\text { del enfoque histórico y crítico } \\
\text { respecto del papel del Estado. } \\
\text { - Proyectos de inserción a } \\
\text { economías lícitas: formación } \\
\text { técnica; configuración de } \\
\text { alianza estatal, comunidades, } \\
\text { entes internacionales y la } \\
\text { empresa privada para orientar } \\
\text { a las comunidades afectadas en } \\
\text { su proceso de superación de } \\
\text { pobreza y marginalidad. }\end{array}$ & $\begin{array}{l}\text { - Articulación entre la RRI y el PNIS en } \\
\text { objetivos y temporalidades. } \\
\text { - Modelo de desarrollo alternativo de } \\
\text { carácter nacional para la articulación } \\
\text { e inclusión de proyectos productivos } \\
\text { sostenibles y estructurales de largo } \\
\text { plazo para el fortalecimiento de la } \\
\text { economía campesina. } \\
\text { - Desconocimiento de la negativa } \\
\text { relación existente entre las economías } \\
\text { extractivas y los cultivos de uso ilícito. }\end{array}$ \\
\hline
\end{tabular}

\footnotetext{
${ }^{3} \mathrm{Su}$ postura fue presentada ante la Asamblea General de la Organización de las Naciones Unidas (2010, septiembre 24), la Oficina de las Naciones Unidas Contra la Droga y el Delito en 2016 y la Organización de Estados Americanos en 2012, y aunque no logró obtener el apoyo suficiente como para que el país se posicionara como un policy maker, fue un primer paso para situar a Colombia como un actor independiente y estratégico dentro de la gobernanza internacional de las drogas (Zambrano et al., 2017, p. 18).
} 
Cuadro 1. (Continuación).

\begin{tabular}{|c|c|c|}
\hline $\begin{array}{c}\text { El Acuerdo de paz } \\
\text { sobre el fenómeno } \\
\text { de los cultivos de uso } \\
\text { ilícito }\end{array}$ & $\begin{array}{c}\text { Avances del PNIS } \\
\text { en el posacuerdo } \\
\text { Enfoque de paz híbrida }\end{array}$ & $\begin{array}{c}\text { Desafíos del PNIS } \\
\text { en el posacuerdo } \\
\text { Enfoque de paz liberal }\end{array}$ \\
\hline $\begin{array}{l}\text { - Enfoque territorial - } \\
\text { descentralización- } \\
\text { - Consideración de } \\
\text { las experiencias } \\
\text { regionales en el } \\
\text { planteamiento de } \\
\text { soluciones al problema } \\
\text { de los cultivos de uso } \\
\text { ilícito. }\end{array}$ & $\begin{array}{l}\text { - Descentralización: En la } \\
\text { implementación de la política } \\
\text { vinculada a los PISDA y } \\
\text { consejos y asambleas en } \\
\text { el ámbito municipal. Y en } \\
\text { los procesos de asignación } \\
\text { monetaria mediante las Juntas } \\
\text { Administradoras Locales (JAC). } \\
\text { - Movimientos estatales hacia el } \\
\text { veto sobre el uso del glifosato } \\
\text { como mecanismo más costoso, } \\
\text { con implicaciones sociales } \\
\text { y la evasión a soluciones } \\
\text { contextualizadas. }\end{array}$ & $\begin{array}{l}\text { - Implementación y diagnóstico } \\
\text { derivaron más importancia el PDET. } \\
\text { - Articulación en la planeación } \\
\text { participativa y la construcción } \\
\text { conjunta con actores claves de cada } \\
\text { territorio. } \\
\text { - Acción territorial desde una visión } \\
\text { centralista -top-down-, tradicional. } \\
\text { - Recursos focalizados y } \\
\text { asistencialistas para las familias que } \\
\text { no se articulan con los proyectos y } \\
\text { reformas estructurales. } \\
\text { - Zonas Futuro de intervención } \\
\text { integral, que focaliza el desarrollo } \\
\text { territorial en la securitización y } \\
\text { militarización. }\end{array}$ \\
\hline $\begin{array}{l}\text { - Creación de } \\
\text { consensos de } \\
\text { alcance global por } \\
\text { los actores afectados } \\
\text {-transnacionalidad } \\
\text { y compromiso } \\
\text { internacional-. } \\
\text { - Crear una } \\
\text { conferencia } \\
\text { internacional en el } \\
\text { marco de la ONU. }\end{array}$ & $\begin{array}{l}\text { - Conferencias internacionales } \\
\text { durante el gobierno Santos } \\
\text { sobre el cambio en la } \\
\text { política de drogas, la } \\
\text { descriminalización, el NO } \\
\text { al prohibicionismo y la } \\
\text { consideración sobre las fuentes } \\
\text { reales de los cultivos de uso } \\
\text { ilícito, sensibilización global. } \\
\text { - Se empieza a hablar con más } \\
\text { fuerza y globalmente sobre } \\
\text { la guerra perdida contra las } \\
\text { drogas. Panorama cada vez } \\
\text { más favorable para alternativas } \\
\text { de legalización de las drogas. }\end{array}$ & $\begin{array}{l}\text { - Blindaje en la normativa } \\
\text { internacional que restringe alternativas } \\
\text { a la guerra contra las drogas. Un } \\
\text { enfoque prohibicionista, dependiente } \\
\text { y asimétrico en la relación países } \\
\text { consumidores versus países } \\
\text { productores. } \\
\text { - Debate nacional e internacional } \\
\text { sobre legalización y prohibicionismo } \\
\text { de drogas de uso ilícito. } \\
\text { - Control de los cultivos de uso ilícito } \\
\text { como agente en el condicionamiento } \\
\text { de las relaciones internacionales y } \\
\text { en la dinámica de campañas para el } \\
\text { cambio político. }\end{array}$ \\
\hline $\begin{array}{l}\text { - Enfoque diferencial } \\
\text { étnico y de género. } \\
\text { - Formulación de una } \\
\text { política que reconoce } \\
\text { particularidades de } \\
\text { género, procedencia } \\
\text { étnica y geográfica en } \\
\text { la vinculación con la } \\
\text { economía de la coca. }\end{array}$ & $\begin{array}{l}\text { - Ha habido mayores estímulos } \\
\text { para el cumplimiento de } \\
\text { derechos como la autonomía, } \\
\text { la consulta previa, la } \\
\text { participación, gobierno propio, } \\
\text { desarrollo étnico y territorial. }\end{array}$ & $\begin{array}{l}\text { - Compromiso real y efectivo hacia las } \\
\text { comunidades sobre su permanencia } \\
\text { en sus territorios ancestrales y a la } \\
\text { comprensión y articulación a su } \\
\text { cosmovisión } \\
\text { - Incumplimiento de planes y } \\
\text { proyectos. } \\
\text { - Política represiva que prolonga y } \\
\text { agudiza la crisis social y humanitaria } \\
\text { de las comunidades. } \\
\text { - Integrar a la formulación del PNIS } \\
\text { el enfoque de género, el programa se } \\
\text { remite a un enfoque familiarista. }\end{array}$ \\
\hline
\end{tabular}


Cuadro 1. (Continuación).

\begin{tabular}{|c|c|c|}
\hline $\begin{array}{l}\text { El Acuerdo de paz } \\
\text { sobre el fenómeno } \\
\text { de los cultivos de uso } \\
\text { ilícito }\end{array}$ & $\begin{array}{l}\text { Avances del PNIS } \\
\text { en el posacuerdo } \\
\text { Enfoque de paz híbrida }\end{array}$ & $\begin{array}{c}\text { Desafíos del PNIS } \\
\text { en el posacuerdo } \\
\text { Enfoque de paz liberal }\end{array}$ \\
\hline $\begin{array}{l}\text { - Tratamiento penal } \\
\text { diferencial a los } \\
\text { eslabones más } \\
\text { débiles de la cadena } \\
\text { del narcotráfico } \\
\text {-cultivadores y } \\
\text { consumidores-. }\end{array}$ & $\begin{array}{l}\text { - Permanencia de la } \\
\text { Jurisdicción Especial para la } \\
\text { paz y la Unidad Especial de } \\
\text { Investigaciones de la Fiscalía. } \\
\text { - Formulación del proyecto } \\
\text { de ley de tratamiento penal } \\
\text { diferenciado para pequeños } \\
\text { cultivadores de plantaciones de } \\
\text { uso ilícito. }\end{array}$ & $\begin{array}{l}\text { - Estancamiento del proyecto de ley } \\
\text { de tratamiento penal diferenciado a } \\
\text { pequeños cultivadores que garantiza } \\
\text { el seguimiento a la gobernanza liberal } \\
\text { de la amenaza contra las drogas en el } \\
\text { ámbito internacional. }\end{array}$ \\
\hline $\begin{array}{l}\text { - Enfoque de salud } \\
\text { pública y prevención } \\
\text { de daños. Solución } \\
\text { desde un enfoque de } \\
\text { derechos humanos, } \\
\text { implicando a todos } \\
\text { los eslabones de la } \\
\text { cadena. }\end{array}$ & $\begin{array}{l}\text { - La formulación de la } \\
\text { política pública del actual } \\
\text { gobierno contiene dentro de } \\
\text { sus pilares la consideración } \\
\text { de la cadena de valor del } \\
\text { narcotráfico, en el marco de la } \\
\text { política los enfoques son los } \\
\text { derechos humanos, la salud } \\
\text { pública, seguridad ciudadana, } \\
\text { desarrollo territorial y } \\
\text { humano y participación de las } \\
\text { comunidades involucradas. }\end{array}$ & $\begin{array}{l}\text { - Visión liberal de la política } \\
\text { antidrogas orientada a la erradicación } \\
\text { total de cultivos de uso ilícito, sin } \\
\text { esquemas graduales o mixtos. } \\
\text { - Segmentación de políticas } \\
\text { evidenciada en que las estrategias } \\
\text { para implementar el punto } 4 \text { del } \\
\text { Acuerdo se enfocan en territorios de } \\
\text { producción o cultivo, no en las fases o } \\
\text { territorios de intermediación y tráfico. }\end{array}$ \\
\hline $\begin{array}{l}\text { - Reconocimiento } \\
\text { de usos ancestrales } \\
\text { y tradicionales de la } \\
\text { hoja de coca. }\end{array}$ & $\begin{array}{l}\text { - Reconocimiento de los usos } \\
\text { ancestrales de la hoja de coca } \\
\text { en sembrados de no más de } \\
20 \text { plantas. Ley } 30 \text { de 1986; } \\
\text { Sentencia C-882/11, derecho } \\
\text { al uso ancestral de la hoja de } \\
\text { coca. }\end{array}$ & $\begin{array}{l}\text { - Ausencia de regulación consciente y } \\
\text { efectiva sobre los usos ancestrales de } \\
\text { la hoja de coca. } \\
\text { - Regulación clara sobre la posibilidad } \\
\text { lícita la producción y venta de } \\
\text { productos a base de la hoja de coca. }\end{array}$ \\
\hline $\begin{array}{l}\text { - Mitigación de daños } \\
\text { ambientales. }\end{array}$ & $\begin{array}{l}\text { - Elaboración de proyectos } \\
\text { productivos para el desarrollo } \\
\text { sostenible en asocio } \\
\text { con la comunidad y sus } \\
\text { conocimientos locales. }\end{array}$ & $\begin{array}{l}\text { - Uso de glifosato para la erradicación } \\
\text { forzosa, con el fin de entregar } \\
\text { resultados más rápidos en cuanto a la } \\
\text { disminución de cultivos de uso ilícito. }\end{array}$ \\
\hline
\end{tabular}

Fuente: elaboración propia.

\section{La política de focalización del PNIS como solución neoliberal frente a los cultivos ilícitos}

La implementación de programas para la sustitución voluntaria de cultivos de uso ilícito está formulada desde un enfoque de focalización del gasto de corte neoliberal. Esto evidencia el fortalecimiento de la 
visión del Estado que en las últimas décadas ha prevalecido frente a programas de subsidio a la demanda, en este caso, las familias vinculadas al PNIS como receptoras de recursos del Estado para que puedan acceder individualmente al mercado de bienes y servicios lícitos. Lo anterior, en una evidente desarticulación con el subsidio a la oferta, que en este caso haría referencia a la tierra o al programa de inversiones de la RRI que se ve representado en el punto 1 del Acuerdo, problema que será abordado más adelante.

Los mecanismos de distribución de recursos a través del PNIS siguen el mismo modelo que se ha dado en el marco de la descentralización administrativa en relación con las denominadas transferencias monetarias condicionadas (Chaves y Hoyos, 2019, junio 24-26): una política social diseñada por la banca multilateral a finales de la década 1980, que rápidamente se adoptó en casi todos los Estados latinoamericanos como uno de los engranajes centrales de las políticas sociales neoliberales.

En Colombia, los programas de transferencias condicionadas están dirigidos a las poblaciones rurales y urbanas, especialmente a regiones afectadas por el conflicto armado. Se iniciaron en 2002 con el nombre de Familias Guardabosques en las áreas rurales y de Familias en Acción en las urbanas. El programa de desmovilización individual de combatientes de grupos armados, que se puso en marcha ese mismo año, utilizó como ejemplo las transferencias condicionadas como parte de sus instrumentos de reintegración (Chaves y Hoyos, 2019, junio 24-26). Aunque analíticamente las transferencias fiscales territoriales, que también se pueden denominar jurisdiccionales, y las transferencias monetarias condicionadas, de orden familiar-individual, responden a lógicas diferentes, convergen en la centralidad que le otorgan al dinero en la construcción de ciudadanía e incluso en su mediación en la realización de futuros viables para la gente:

Las transferencias monetarias condicionadas constituyen un modelo de política social inscrito completamente en la lógica neoliberal de disminución del riesgo y de contención política de los pobres. En su discurso, las transferencia monetarias condicionadas giran en torno a tres principios básicos: 1 . la distribución de dinero como punto de despegue hacia un mayor bienestar de los pobres (alimentación, salud, educación), 2. la producción de información sobre este tipo de población, pieza central de la generación de «gobernanza» en el 
sentido en que la proponen instituciones multilaterales como el Banco Interamericano de Desarrollo, y por último, un enfoque de género asociado al papel central de las madres en la mejoría de las condiciones sociales de los beneficiarios (Chaves y Hoyos, 2019, junio 24-26).

Margarita Chaves y Juan Hoyos (2019, junio 24-26) sostienen que las transferencias monetarias comenzaron a implementarse como un experimento de política social en México a finales de la década de 1990 y rápidamente se expandieron al resto del continente. Los programas Progresa —-más adelante rediseñado como Oportunidades- en México y Bolsa de Familia en Brasil son, tal vez, los más conocidos.

Siguiendo el supuesto anterior, los cuestionamientos que surgen hoy frente al futuro de la implementación y el cumplimiento a las familias vinculadas al PNIS corresponden a las fallas de origen, entre las que se encuentran: el énfasis en la entrega de los subsidios a las familias y las deudas sobre la inversión en bienes y servicios públicos; la falta de claridad sobre el financiamiento de la política de sustitución de cultivos ilícitos; la falta de coordinación entre la erradicación forzada y la sustitución sin una secuencia adecuada para su despliegue-; la cooptación de los espacios participativos y los intermediarios; y la inseguridad jurídica para los beneficiarios y funcionarios. Otros problemas relevantes son la evidente desconexión del PNIS con la RRI; la ausencia de indicadores y metas vinculadas a la transformación de los territorios; la falta de claridad sobre los criterios de priorización y focalización territorial y la ausencia de una hoja de ruta para la implementación del PNIS (Garzón, Gélvez y Bernal, 2019, pp. 11-12).

Un factor que, por ejemplo, ha debilitado la legitimidad de los programas en las zonas cocaleras se evidencia en la suspensión del programa a 13350 familias en 2019 debido a cuestiones como inconsistencias en el puntaje en el Sistema de Identificación de Potenciales Beneficiarios para Programas Sociales (Sisben), ${ }^{4}$ irregularidades en registro, documentación e incumplimiento por parte de las familias de los compromisos adquiridos (Garzón, Gélvez y Bernal, 2019, p. 20).

\footnotetext{
${ }^{4}$ Se trata de un programa de focalización a través del cual se realiza la clasificación de la población, teniendo en cuenta sus condiciones de vida e ingresos. Con esta información se focaliza la inversión social y se busca garantizar su asignación a los más necesitados.
} 
Otra de las falencias evidentes en la articulación de ambos programas radica en la formulación de sus temporalidades, pues mientras la RRI está pensada a diez años, el PNIS tenía dos años para ejecutarse y se centraba específicamente en la erradicación de cultivos ilícitos (Garzón y Álvarez, 2017 , p. 20). Dicha incompatibilidad temporal es contradictoria, puesto que el tiempo de solución del problema de los cultivos ilícitos no puede ser menor al de la RRI, de lo contrario, el enfoque de solución no es estructural, sino que termina privilegiando el tratamiento punitivo y asistencialista, como en efecto se vive actualmente en la totalidad de los territorios del país. La falta de cohesión entre el PNIS y la RRI también evidencia que, aunque el PNIS se planteó en permanente relación con la RRI y los programas de transformación del campo colombiano, el tema de la sustitución de cultivos sigue siendo abordado desde un enfoque antinarcóticos.

Las dificultades en la implementación del PNIS y el incumplimiento de los plazos evidencian, asimismo, que se ha tardado más tiempo del estipulado y que, a casi cuatro años de la firma del Acuerdo, 73817 (89,8\%) de las 99097 familias inscritas en el programa recibieron un primer pago de COL\$1 000000 estipulados por 12 meses, pero en el año 2020 tan solo $49768(60,5 \%)$ de las familias recibieron la totalidad de los pagos. Los departamentos de menor cumplimiento en los pagos son justamente aquellos donde el cultivo ha aumentado: Norte de Santander, con $71 \%$ de cumplimiento a 532 familias, de las 3000 inscritas; y Cauca, con 18,6\% de cumplimiento a 1057 familias, de 5691 inscritas (UNODC, 2020).

En cuanto al componente asistencialista del programa, el Servicio de Asistencia Técnica Integral Ilegó ocho meses después del primer pago, el componente de autosostenimiento trece meses después y el proyecto de ciclo corto diecinueve meses después. De acuerdo con estimaciones del propio programa, los trámites administrativos y operativos ocasionaron que la hoja de ruta se acabara implementando en cuatro años y no en dos, como se comprometió el Gobierno con las comunidades. Estas brechas de implementación han tenido significativas consecuencias para el proceso de sustitución. Sin la contratación de la asistencia técnica no se puede avanzar en los demás componentes y por eso las familias están terminando el ciclo de pagos sin contar aún con un proyecto productivo que pueda garantizar los ingresos básicos para su subsistencia (Garzón, Gélvez y Bernal, 2019, p. 19). 


\section{La participación legitimadora como desafío de la paz liberal frente al problema de los cultivos ilícitos}

Entre las variables neoliberales que predominan en las reformas estructurales de Colombia y América Latina desde la década de 1990, se identifica el principio de la participación legitimadora y democratizadora que se introduce en los programas de gobierno, pero que resulta en formas contraproducentes de individualismo y fragmentación social que operan como garantes superficiales para la efectiva implementación de las reformas neoliberales (Chaves y Hoyos, 2019, junio 24-26).

La primera estrategia de legitimación liberal de la participación se encuentra en la producción de información sobre la población vulnerable como pieza central de la generación de «gobernanza» en el sentido en que la proponen instituciones multilaterales como el Fondo Monetario Internacional (FMI) o el Banco Interamericano de Desarrollo -las bases de datos que permiten legibilidad, generación de catastros o, incluso, de «memoria» financiera- (Chaves y Hoyos, junio 24-26).

Al respecto, en el Informe de resultados del proceso de selección de [202] organizaciones para la implementación del servicio de asistencia técnica integral (Colombia Renace, 2028) se recogen los principios de producción de información sobre la población afectada por cultivos ilícitos como forma de generación de datos para la «gobernanza internacional de los conflictos», propia de la concepción de la paz (neo)liberal. Pero más allá de esta estrategia, la posibilidad de una transformación participativa derivada del punto 4 del Acuerdo paz no ha logrado, a grandes rasgos, revitalizar el vínculo sociedad-Estado, en el cual las necesidades locales y las iniciativas contextualizadas y participativas deberían priorizarse.

En este sentido, la implementación del punto 4 sobre los cultivos de uso ilícito a través del PNIS ha sido desalentador, pues aunque se firmaron alrededor de treinta acuerdos colectivos y participativos en todo el país para la sustitución de cultivos, en los que las comunidades de manera voluntaria expresaron la intención de sustituir sus cultivos, siempre y cuando las condiciones de desarrollo y oportunidades integrales posibiliten la sostenibilidad del programa (Tobón y Sierra, 2018), a día de hoy tales acuerdos no se han Ilevado a cabo en su mayoría, debido al incumplimiento 
de los principios básicos de concertación y participación donde las comunidades reclaman: a) falta de voluntad política del Gobierno; b) falta de proyectos integrales que vayan más allá de los proyectos productivos que le garanticen a la poblaciones otros bienes y servicios públicos concurrentes para superar las causas asociadas al cultivo ilícito; c) falta de concertación y participación de las comunidades étnicas —indígenas y afrodescendientes-, junto con el reconocimiento de sus particularidades culturales y contextuales; y d) desarticulación entre las entidades del Gobierno, entre otros aspectos (Tobón y Sierra, 2018).

Como contrapunto comparativo, Andrés Bermúdez y Juan Garzón (2020) Ilaman la atención de diez casos exitosos de sustitución de coca en distintos territorios del país. Aunque sus contextos, dinámicas y resultados son variables, se evidencia un punto común de todos los casos: hay una perspectiva participativa del proceso, donde son las comunidades las que encuentran soluciones y posteriormente pueden vincularse a otros ámbitos de la institucionalidad.

Ha sido evidente, por ejemplo, la ineficacia de un enfoque diferencial que bien podría sustentar la concepción de una paz híbrida, localizada y contextual que, por ejemplo, en el caso de las comunidades indígenas vinculadas al programa y que conviven en algunos de los territorios de mayor siembra, suscitan más preguntas que respuestas frente al cumplimiento de estrategias participativas y diferenciales. Uno de los casos más evidentes ha sido el de la comunidad indígena Awá, quienes se negaron a participar del programa pues no se respetó su derecho a la consulta previa ni se ajustó la iniciativa a su cosmovisión originaria (El Turbión, 2019, abril 16).

El otro gran desafío de la implementación del Acuerdo de paz en el tema de sustitución de cultivos y la lógica de la participación legitimadora ha sido el recrudecimiento de la violencia en los territorios comprometidos con el programa, pues con la salida de las FARC-EP de las zonas cocaleras las disputas por el control del mercado de la coca se han trasladado a otros actores armados al margen de la ley. A este complejo escenario se suma la tentativa de rearme de algunos sectores de las FARC-EP, quienes recientemente anunciaron que la tributación para la financiación de la rebelión se aplicaría, en parte, a las economías ilegales, siendo el mercado de la coca uno de los rubros más representativos en esta materia. Jairo Javier Bisbicús, Fiscal de la Unidad Indígena del Pueblo Awá afirmó que: 
Actualmente no existen garantías a la seguridad de los Awá frente a la presión de los nuevos grupos armados que aparecen y que se enriquecen con el negocio de la hoja de coca, hay asesinatos de líderes indígenas y desapariciones [...] esto se origina en los distintos intereses que hay en el territorio, un territorio que se ha convertido en campo de batalla, un territorio que ha servido para todos los grupos armados como corredores estratégicos para mover el narcotráfico, para el tema de la minería [...] todo esto ha costado muertos de nuestros compañeros, desapariciones, un sinnúmero de víctimas, un sinnúmero de niños huérfanos (El Turbión, 2019, abril 16).

En cuanto al campesinado, representado en la Coordinadora Nacional de Cultivadores de Coca, Amapola y Marihuana (Coccam), en 2018 denunciaban incumplimientos a las comunidades vinculadas a la sustitución de cultivos de uso ilícito por dificultades en los desembolsos monetarios, la lenta implementación de los planes de acción inmediata (PAI) y los programas de asistencia técnica, además de los problemas de financiación. Adicionalmente, denunciaban la falencia de las instancias de participación que se proponen en el Decreto reglamentario del programa e incumplimientos en la hoja de ruta acordada para su implementación. De igual forma, denunciaban amenazas y asesinatos, puesto que entre 2017 y 2018 fueron asesinados 47 de sus miembros (Coccam, 2018, marzo 6).

En la zona Pacífico del departamento de Nariño, por ejemplo, las comunidades de municipios como Ipiales y Tumaco viven, por un lado, las amenazas contra aquellos que quieren vincularse a los programas y, por otro, las extorsiones por parte de grupos armados a quienes ya se han integrado y recibieron el apoyo monetario de corto plazo (Ramírez y Vargas, 2019, mayo 9). Esta situación es relatada por una mujer que reside en Tumaco:

Siento que el Estado nos ha abandonado porque en Tumaco, Nariño, estamos azotados por muchos grupos armados de diferentes índoles [...] no salimos de nuestras casas en las tardes, nos da mucho miedo. Entra un Grupo armado y sale otro [...] el Gaula y la Policía [...] han capturado a algunos, se les reconoce, pero nos tienen abandonados porque solo entran cuando la cosa se pone bien caliente y ya se van. [...] Si nos miran hablando con algún militar o policía o fuerza pública también nos amenazan. Cuando se dan cuenta que van a desembolsar la plata, quieren que les den una parte de ese dinero (Ramírez y Vargas, 2019, mayo 9). 
Adicionalmente, los miembros del Consejo Comunitario Alto Mira y Frontera en Tumaco también han sido amenazados, e incluso se conoció el asesinato del líder José Jair Cortés, «quien desarrollaba trabajo pedagógico y de alistamiento para el PNIS» (Ramírez y Vargas, 2019, mayo 9). Una mujer Ilamada Clara que es integrante de este consejo comenta que «lo paradójico es que antes del proceso de paz había violencia y muertos, porque eso nunca ha dejado de haber, pero yo creo que ahora hay más» (Ramírez y Vargas, 2019, mayo 9).

En el marco del confinamiento producto del COVID-19 los campesinos también denunciaron el retorno de operativos de erradicación forzada como una forma de violación a los derechos humanos en los departamentos del Valle del Cauca, Caquetá, Córdoba, Putumayo, Antioquia, Norte de Santander y Nariño, lo que implica un incumplimiento al programa frente a las garantías de seguridad a las familias comprometidas con la sustitución (Coccam, 2020, abril 20).

En términos generales, es importante reconocer que la lógica de la participación que legitima las políticas de corte neoliberal del poscacuerdo en materia de cultivos ilícitos en Colombia no solo debe implicar el diseño de acuerdos participativos con baja expectativa de éxito, sino comprender la complejidad social, económica y cultural de los cocaleros como actores heterogéneos. En el caso del Caquetá, por ejemplo, el cultivo de coca se presenta bajo distintos modelos de legitimación y como alternativa para continuar en el campo mientras se desarrollan otros procesos productivos, como transición a la independencia y fuente de ingresos, o como alternativa de ahorro para migrar a las ciudades (Ciro, 2016).

\section{Conclusiones}

El auge del neoliberalismo como paradigma económico en la década de 1990 que trazó desde Washington las agendas de paz y seguridad para América Latina ha impactado el diseño de políticas públicas en la región y las estrategias de construcción de paz orientadas a la resolución de conflictos. Desde el modelo de paz liberal, como referente hegemónico del capitalismo en la búsqueda de seguridad humana, se han materializado los mecanismos de apertura económica, liberalización y búsqueda de rentabilidad, por lo que estrategias como el Programa Nacional Integral de Sustitución de Cultivos Ilícitos (PNIS) en el caso del posacuerdo colombiano, han seguido el rumbo delineado desde el Norte. 
Cuadro 2. Desafíos de la implementación del PNIS a partir de las variables de focalización y la participación legitimadora.

\begin{tabular}{|c|c|c|}
\hline Variable & Avances & Limitaciones \\
\hline Focalización & $\begin{array}{l}\text { - Aumento del } \\
\text { porcentaje de } \\
\text { sustitución voluntaria } \\
\text { desde la asistencia } \\
\text { técnica y monetaria } \\
\text { de múltiples familias } \\
\text { cocaleras al PNIS. } \\
\text { Algunos departamentos } \\
\text { declarados libres de } \\
\text { coca en } 2020 \\
\text { - Descentralización } \\
\text { de los procesos de } \\
\text { asignación monetaria } \\
\text { mediante las Juntas de } \\
\text { Acción Comunal (JAC). } \\
\text { - Existencia de } \\
\text { programas de asistencia } \\
\text { y generación de } \\
\text { algunos proyectos de } \\
\text { autosostenibilidad en las } \\
\text { economías legales. }\end{array}$ & $\begin{array}{l}\text { - Limitaciones estructurales: } \\
\text { - Distribución familiar de recursos como medida } \\
\text { neoliberal de focalización del gasto, más que } \\
\text { una solución estructural para la vinculación de } \\
\text { economías alternativas y una provisión óptima de } \\
\text { bienes y servicios públicos. } \\
\text { - Falta de articulación entre la RRI (PDET) y el } \\
\text { PNIS, desfase de objetivos y temporalidades } \\
\text { entre ambos; estancamiento de presupuesto y } \\
\text { fragmentación de planes y programas. } \\
\text { - Priorización del enfoque antinarcóticos del PNIS } \\
\text { sobre la agenda de desarrollo rural. } \\
\text { Limitaciones presupuestales en contexto } \\
\text { neoliberal: } \\
\text { - Ausencia de recursos base de carácter nacional } \\
\text { para cumplimiento a los acuerdos firmados } \\
\text { inicialmente y la vinculación de nuevas familias al } \\
\text { programa. } \\
\text { - Inconsistencia en los ciclos de asistencia técnica } \\
\text { y presupuestal manifestada en el retraso de los } \\
\text { pagos. } \\
\text { - Inconsistencia en el componente asistencialista } \\
\text { del programa evidenciado en una falta de } \\
\text { continuidad en los tiempos en los que Ilega cada } \\
\text { componente del programa } \\
\text { - Las familias terminan el ciclo de pagos sin } \\
\text { un proyecto productivo que garantice ingresos } \\
\text { básicos de subsistencia, } \\
\text { Limitaciones burocráticas y tecnocráticas: } \\
\text { - Suspensión de acuerdos a } 13 \text { } 350 \text { familias en } \\
\text { 2019 por irregularidades en la suscripción al } \\
\text { Sisben. } \\
\text { - Poca claridad frente a los plazos de la } \\
\text { vinculación de las familias para acceder a los } \\
\text { beneficios del programa. } \\
\text { - Retrasos en la entrega de subsidios y en la } \\
\text { prestación de asistencia técnica en los proyectos } \\
\text { de desarrollo autosostenible. } \\
\text { - Falta de claridad frente a los proyectos } \\
\text { productivos con las comunidades en territorios } \\
\text { especiales (como PNN). }\end{array}$ \\
\hline
\end{tabular}


Cuadro 2. (Continuación).

\begin{tabular}{|c|c|c|}
\hline Variable & Avances & Limitaciones \\
\hline $\begin{array}{l}\text { Participación } \\
\text { legitimadora }\end{array}$ & $\begin{array}{l}\text { - Firma de } 30 \text { acuerdos } \\
\text { comunitarios y } \\
\text { participativos a nivel } \\
\text { nacional } \\
\text { - Fortalecimiento de } \\
\text { la descentralización: } \\
\text { implementación } \\
\text { vinculada a los } \\
\text { PISDA y los consejos } \\
\text { y asambleas a nivel } \\
\text { municipal. } \\
\text { - Fortalecimiento de } \\
\text { la institucionalidad y } \\
\text { asociatividad de las } \\
\text { comunidades mediante } \\
\text { sindicatos y otros } \\
\text { organismos. } \\
\text { - Producción de } \\
\text { información sobre } \\
\text { población vulnerable }\end{array}$ & $\begin{array}{l}\text { - Limitaciones participativas: } \\
\text { - Incumplimiento de compromisos de } \\
\text { concertación y participación con las } \\
\text { comunidades. } \\
\text { - Falta de concertación y participación con las } \\
\text { comunidades étnicamente diferenciadas. } \\
\text { - Falta de articulación al interior del Gobierno. } \\
\text { - Baja asociatividad que regule el proceso de } \\
\text { sustitución y tendencia al clientelismo político } \\
\text { con las FARC-EP, donde el Estado no regula } \\
\text { fuertemente los cultivos de coca. } \\
\text { - Limitaciones referidas a la violencia y el } \\
\text { conflicto: } \\
\text { - Localización de nuevos grupos armados en } \\
\text { algunas de las zonas cocaleras. } \\
\text { - Aumento de las amenazas, extorsión y asesinatos } \\
\text { a comunidades y líderes sociales asociados al } \\
\text { programa. } \\
\text { - Incompatibilidad entre medidas de sustitución } \\
\text { voluntaria, de erradicación forzosa (acompañada } \\
\text { de militarización) y de criminalización del } \\
\text { cultivador socava el espíritu participativo y genera } \\
\text { desconfianza. } \\
\text { - Estancamiento de la Ley } 197 \text { de } 2018 \text { sobre } \\
\text { tratamiento penal diferenciado a pequeños } \\
\text { cultivadores (TPD) que reduce las garantías } \\
\text { sociales y la confianza participativas de las } \\
\text { comunidades cocaleras. } \\
\text { - Existencia de valores y legitimidades alternativas } \\
\text { que construyen las comunidades campesinas para } \\
\text { resistir o confrontar discursos oficiales sobre la } \\
\text { ilegalidad de la coca. }\end{array}$ \\
\hline
\end{tabular}

Fuente: elaboración propia.

El Acuerdo de paz en Colombia se acerca a la formulación de una nueva concepción híbrida y contextualizada de la paz frente al problema de las drogas y los cultivos de uso ilícito que incluye el reconocimiento de las causas históricas que facilitaron la vinculación de poblaciones vulnerables con las economías ilegales, una visión descentralizada de las políticas con un enfoque transversal a la Reforma Rural Integral (RRI) apalancada por la creación de espacios y acuerdos locales para la implementación del PNIS, el reconocimiento a las particularidades étnicas y sociales de las comunidades 
cocaleras y un enfoque de salud pública en lo referente a la prevención y no estigmatización de los cultivadores y consumidores. Asimismo, el Acuerdo dejó plasmada una visión internacional del fenómeno, enfatizando en el enfoque de corresponsabilidad entre países productores y consumidores en la formulación de una política antidrogas menos punitiva, considerando los errores precedentes de intentos de erradicación desde la criminalización y la militarización de las zonas cocaleras.

Lamentablemente, en el marco de los lineamientos democráticos, atención y desarrollo de proyectos productivos a través de la asignación monetaria -focalización neoliberal de recursos- y la lógica de la participación legitimadora, el PNIS ha reproducido homogéneamente la concepción neoliberal sobre el rol del Estado en la superación de la problemática de los cultivos ilícitos en Colombia. Por una parte, la política de focalización del gasto ha evidenciado los desfases técnicos, presupuestales y temporales, así como la lógica asistencialista del programa de sustitución pacífica de los cultivos ilícitos. Por otra parte, la «participación legitimadora», que también ha operado como principio rector de la democracia de la paz (neo)liberal, ha evidenciado una visión centralista y burocrática que busca legitimar políticas a través de procesos participativos que se distancian de la idea de un posacuerdo construido desde las bases sociales y entendido como conjunto de reformas orientadas a la construcción de una paz contextualizada y territorial.

Una aproximación al problema de los cultivos ilícitos a partir de mecanismos de la paz híbrida aparece como alternativa a los desafíos que sugiere la fallida estrategia de sustitución del PNIS. Surgen, no obstante, amplios interrogantes sobre la pertinencia de abordar las diversas realidades cocaleras desde un solo enfoque de política pública, cuando las causas del cultivo son tan diversas como los territorios en los que se presentan. Reflexionar sobre cómo evaluar de mejor forma esas políticas y sus aspectos metodológicos constituye una tarea pendiente para plantear soluciones al problema de las drogas ilícitas en el contexto del posacuerdo colombiano.

\section{Referencias bibliográficas}

1. Agudelo Taborda, Jairo y Riccardi, Davide. (2019). La cooperación internacional para la paz en Colombia: los casos de Estados Unidos y de la Unión Europea (19982016). Geopolítica(s), 10 (1), pp. 107-134. https://doi.org/10.5209/GEOP.61477 
2. Asamblea General de la Organización de las Naciones Unidas. (2010, septiembre 24). Intervención del Presidente de la República de Colombia, S. E. Sr. Juan Manuel Santos Calderón, ante la Asamblea General de la Organización de las Naciones Unidas en su Sexagésimo Quinto Período de Sesiones Ordinarias. Cancillería de Colombia. https://nuevayork-onu.mision.gov.co/intervencion-del-presidente-larepublica-colombia-se-sr-juan-manuel-santos-calderon-ante-la-asamblea

3. Bermúdez, Andrés y Garzón, Juan (2020). El catálogo de las pequeñas soluciones: Alternativas para sustituir los cultivos de coca en Colombia. Bogotá, D. F.: Fundación Ideas para la Paz Fundación Friedrich Ebert. http://library.fes.de/pdf-files/ bueros/kolumbien/16314.pdf

4. Call, Charles \& Cousens, Elizabeth. (2008). Ending Wars and Building Peace: International Responses to War-Torn Societies. International Studies Perspectives, 9 (1), pp. 1-21. https://doi.org/10.1111/j.1528-3585.2007.00313.x

5. Ciro, Estefanía. (2016). Cultivando coca en el Caquetá: vidas y legitimidades de la actividad cocalera. [Tesis inédita de doctorado]. Universidad Nacional Autónoma de México, México, D. F. https://www.academia.edu/39739068/Cultivando_coca_ en_el_Caquet\%C3\%A1_vidas_y_legitimidades_de_la_actividad_cocalera

6. Colombia Renace. (2018). Informe de Resultados del Proceso de Selección de Organizaciones para la Implementación del Servicio de Asistencia Técnica Integral. http://www.posconflicto.gov.co/consejeria/Paginas/Proceso-de-Seleccion-Asistenciatecnica-PNIS.aspx

7. Coordinadora Nacional de Cultivadores de Coca, Amapola y Marihuana (Coccam). (2018, marzo 6). En riesgo el programa nacional integral de sustitución PNIS. Indepaz. http://www.indepaz.org.co/wp-content/uploads/2018/03/ComunicadoCOCCAM-6-marzo-2018.pdf

8. Coordinadora Nacional de Cultivadores de Coca, Amapola y Marihuana (Coccam). (2020, abril 20). Coordinadora Nacional de Cultivadores Coca, Amapola y Marihuana y sus organizaciones de base a la población colombiana y al Gobierno nacional. Movice. https://movimientodevictimas.org/coordinadora-nacional-decultivadores-de-coca-marihuana-y-amapola-coccam-envia-mensaje-a-la-opinionpublica-y-al-gobierno-nacional/

9. Chaves, Margarita y Hoyos, Juan. (2019, junio 24-26). Transferencias económicas como dispositivos de gobierno en los márgenes del estado. Seminario Tres décadas de transformaciones en América Latina: gobierno, subjetividades, márgenes y neoliberalismos. Universidad de San Pablo, San Pablo, Brasil.

10. Doyle, Michael W. (1983a). Kant, Liberal Legacies and Foreign Affairs. Philosphy and Public Affairs, 12 (3), pp. 205-235. https://www.jstor.org/stable/2265298

11. Doyle, Michael W. (1983b). Kant, Liberal Legacies and Foreign Affairs, Part 2. Philosphy and Public Affairs, 12 (4), pp. 323-353. https://www.jstor.org/ stable/2265377 
12. DW. (2020, junio 17). Descienden los cultivos de hoja de coca en Colombia, aunque sube la producción de droga. https://www.dw.com/es/descienden-loscultivos-de-hoja-de-coca-en-colombia-aunque-sube-la-producci\% C3\%B3n-dedroga/a-53851628

13. El Turbión. (2019, abril 16). ¿Por qué los Awá no se le midieron al PNIS? Verdad Abierta. https://verdadabierta.com/por-que-los-indigenas-awa-no-se-lemidieron-al-pnis/

14. Garzón, Juan y Álvarez, Eduardo. (2017). ¿En qué va la sustitución de cultivos ilícitos? Principales avances, desafíos y propuestas para hacerles frente. Informe trimestral 2. Fundación Ideas para la Paz (FIP). http://cdn.ideaspaz.org/media/website/ document/5a0c456a3dd37.pdf

15. Garzón, Juan., Gélvez, Juan y Bernal, José. (2019). ¿En qué va la sustitución de cultivos ilícitos? Desafíos, dilemas actuales y la urgencia de un consenso. Informe trimestral 3. Fundación Ideas para la Paz (FIP). http://ideaspaz.org/media/website/ FIP_sustitucion_VOL06.pdf

16. Gobetti, Zeno. (2009). Una revisión de la teoría de la paz democrática. CS, 3 (3), pp. 39-74. https://doi.org/10.18046/recs.i3.425

17. Gobierno de Colombia y FARC-EP. (2016). Acuerdo final para la terminación del conflicto y la construcción de una paz estable y duradera. Jurisdicción Especial para la Paz. https://www.jep.gov.co/Marco\%20Normativo/Normativa_v2/01\%20 ACUERDOS/Texto-Nuevo-Acuerdo-Final.pdf? $c s f=1 \& \mathrm{e}=0 \mathrm{fpYA0}$

[210] 18. Gutiérrez, Francisco; Machuca, Diana Ximena y Cristancho, Sebastián. (2019). ¿Obsolescencia programada? La implementación de la sustitución y sus inconsistencias. Análisis Político, 32 (97), pp. 136-160. https://doi.org/10.15446/ anpol.v32n97.87197

19. Insuasty R., Alfonso y Sánchez, David. (2018, octubre 29). Acuerdo de Paz en Colombia: ¿una oportunidad pérdida? Kavilando. https://kavilando.org/lineaskavilando/conflicto-social-y-paz/6477-acuerdo-de-paz-en-colombia-una-oportunidadperdida

20. Keohane, Robert. (1989). Neoliberal Instititionalism: A Perspective on World Politics, In: International Institutions and State Power. Essays in International Relations Theory (pp.1-21). Boulder: Westview. https://doi.org/10.4324/9780429032967-1

21. Kurtenbach, Sabine. (2010). Why is Liberal Peacebuilding so Difficult? Some Lessons from Central America. European Review of Latin American and Caribbean Studies, 88, pp. 95-110. https://doi.org/10.18352/erlacs.9597

22. Lederach, Jean Paul. (2012). The Origins and Evolution of Infraestructures of Peace: A Personal Reflection. Journal of Peacebuilding and Development, 7 (3), pp. 8-13. https://doi.org/10.1080/15423166.2013.767604

23. Mac Ginty, Roger. \& Sanghera, Gurchathen. (2012). Hybridity in Peacebuilding and Development: An Introduction. Journal of Peacebuilding and Development, 7 (2), pp. 3-8. https://doi.org/10.1080/15423166.2012.742800 
24. Mac Ginty, Roger. (2010). Hybrid Peace: The interaction between TopDown and Buttom-Up Peace. Security Dialogue, 41 (4), pp. 391-412. https://doi. org/10.1177/0967010610374312

25. Mac Ginty, Roger. (2012). Routine Peace: Technocracy and Peacebuilding. Cooperation and Conflict, 47 (3), pp. 287-308. https://doi. org/10.1177/0010836712444825

26. Mac Ginty, Roger \& Richmond, Oliver. (2013). The Local Turn in Peace Building: A Critical Agenda for Peace. Third World Quarterly, 34 (5), pp. 763-783. https://doi.org/10.1080/01436597.2013.800750

27. Malone, David \& Nitzschke, Heiko. (2009). Economic Agendas in Civil Wars: What We Know, What We Need to Know. In: Addison, Tony \& Brück, Tilman (Eds.). Making Peace Work: The Challenges of Social and Economic Reconstruction (pp. 3150). New York: Palgrave-Macmillan. https://doi.org/10.1057/9780230595194_3

28. Méndez Blanco, Yenly Angélica; Silva Aldana, Johana y González Suárez, Ana María. (2019). El Programa Nacional Integral de Sustitución de Cultivos Ilícitos (PNIS): balance, retrocesos y desfiguraciones. En: Estrada Álvarez, Jairo (coord.). El Acuerdo de paz en Colombia. Entre la perfidia y la potencia transformadora (pp. 131160). Buenos Aires: Clacso. https://doi.org/10.2307/j.ctvt6rknp.8

29. Oficina de las Naciones Unidas contra la Droga y el Delito (UNODC). (2019). Monitoreo de territorios afectados por cultivos ilícitos 2018. https://www.unodc. org/documents/colombia/2019/Agosto/Informe_de_Monitoreo_de_Territorios_ Afectador_por_Cultivos_llicitos_en_Colombia_2018_.pdf

30. Oficina de las Naciones Unidas contra la Droga y el Delito (UNODC). (2020). Informe N. ${ }^{\circ} 21$. Programa Nacional Integral de Sustitución de Cultivos Ilícitos - PNIS. https://www.unodc.org/documents/colombia/2020/Mayo/INFORME_EJECUTIVO_ PNIS_No._21.pdf

31. Pugh, Michael. (2011). Local Agency and Political Economies of Peacebuilding. Studies in Ethnicity and Nationalism, 11 (2), pp. 308-320. https://doi.org/10.1111/ j.1399-6576.2011.01113.x

32. Radio Nacional de Colombia. (2020, junio 17). Cultivos de uso ilícito se redujeron un $9 \%$ en el último año: UNODC. http://cms.radionacional.co/actualidad/ cultivos-de-uso-ilicito-se-redujeron-un-9-en-el-ultimo-ano-unodc

33. Ramírez, Camila y Vargas, Yovana. (2019, mayo 9). En Tumaco no saben qué pasará con el PNIS. Verdad Abierta. https://verdadabierta.com/tumaco-no-sabenpasara-pnis/

34. Richmond, Oliver. (2006). The Problem of Peace: Understanding the «Liberal Peace». Conflict, Security \& Development, 6 (3), pp. 291-314. https://doi. org/10.1080/14678800600933480

35. Richmond, Oliver. (2010a). Palgrave advances in Peacebuilding: Critical Developments and Approaches. Basingstoke: Plagrave Macmillan. 
36. Richmond, Oliver. (2010b). Resistance and the Post-liberal Peace. Millennium, 38 (3), pp. 665-692. https://doi.org/10.1177/0305829810365017

37. Richmond, Oliver. (2011a). A Post-Liberal Peace. Oxon. Routledge. https:// doi.org/10.4324/9780203810262

38. Richmond, Oliver. (2011b). Becoming a Liberal, Unbecoming Liberalism: Liberal Local-Hybridity Via the Everyday as a Response of the Paradoxes of Liberal Peacebuilding. In: Tadjbakish, Shahrbanou (Ed.). Rethinking the Liberal Peace: External Models and Local Alternatives (pp.37-57). Oxon. Routledge.

39. Richmond, Oliver. (2012). Missing Links. Peace Infrastructures and Peace Formation. In: Unger, Barbara; Lundström, Stina; Planta, Katrin \& Austin, Beatrix (Eds.). Peace Infrastructures. Assessing Concept and Practice (pp. 22-29). Berlin: Berghof Foundation.

40. Richmond, Oliver. (2013). Peace Formation and Local Infrastructures for Peace. Alternatives: Global, Local, Political, 38 (4), pp. 271-287. https://doi. org/10.1177/0304375413512100

41. Richmond, Oliver. (2015). Decolonizing Security and Peace MonoEpistemology Versus Peace Formation. In: Rumelili, Bahar (Ed.). Conflict Resolution and Ontological Security: Peace Anxieties (pp. 164-184). New York: Routledge.

43. Rocha, Ricardo. (2016). Informe N. ${ }^{\circ}$ de progreso de la asistencia técnica espe42. cializada. Una visión de la Política de Cultivos llícitos en el Postconflicto. Bogotá, D. C.: Departamento de la Prosperidad Social.

[212 ] 44. Russett, Bruce. (1993a). The Fact of Democratic Peace. In: Russett, Bruce. Grasping the Democratic Peace: Principles for a Post-Cold War World (pp. 3-23). Princeton: Princeton University. https://doi.org/10.1515/9781400821020

45. Russett, Bruce. (1993b). Why Democratic Peace? In: Russett, Bruce. Grasping the Democratic Peace: Principles for a Post-Cold War World (pp. 24-42). Princeton: Princeton University. https://doi.org/10.1515/9781400821020-003

46. Russett, Bruce. (1993c). The Future of the Democratic Peace. In: Russett, Bruce. Grasping the Democratic Peace: Principles for a Post-Cold War World (pp. 119-138). Princeton: Princeton University. https://doi.org/10.1515/9781400821020-007

47. Semana. (2020, 17 de junio). UNODC: cultivos de coca disminuyeron $9 \%$ en Colombia en 2019. https://www.semana.com/pais/articulo/cuantas-hectareas-decultivos-ilicitos-hay-en-colombia-2020/289871/

48. Tobón, Gabriel y Sierra, Ana. (2018). Implementación del Programa Nacional Integral de Sustitución de Cultivos de Uso llícito -PNIS-. Observatorio de Territorios Étnicos y Campesinos. https://etnoterritorios.org/CentroDocumentacion. . hhtml?apc $=\mathrm{x}$ $\mathrm{xx}-1-\& \mathrm{x}=1261$

49. Triana, Alejandro. (2014). Paz híbrida Multiactor: un modelo posible frente a la construcción de paz en escenarios de posnegociación a la luz del caso colombiano. [Tesis de pregrado inédito]. Pontificia Universidad Javeriana, Bogotá, D. C. 
50. Verdes-Montenegro, Francisco. (2015). Securitización: agendas de investigación abiertas para el estudio de la seguridad. Relaciones Internacionales, 29, pp. 111-131. https://revistas.uam.es/relacionesinternacionales/article/view/5273

51. Zabalza, Guillermina y Ravioli, Ana. (2005). Reflexiones sobre «la paz perpetua». Cartapacio de Derecho, 8, pp. 1-8.

52. Zambrano, Juliana; Zambrano, Dayana; Ospina, Guillermo; Perilla, Jairo y Ortiz, Santiago. (2017). Colombia y la política de drogas: del policy-taking al policymaking a través de una aproximación desde la geopolítica crítica y el constructivismo en la política exterior. [Tesis inédita de maestría]. Universidad del Rosario, Bogotá, D. C. https://www.urosario.edu.co/facultad-de-estudios-internacionales/Programas/ Maestrias/Maestria-en-Estudios-Politicos-e-Internacionales/Documentos/TPDColombia-y-la-Politica-de-Drogas/ 